\title{
ARTE E EDUCAÇÃO NA CULTURA SURDA
}

ART AND EDUCATION IN DEAF CULTURE

\author{
${ }^{1}$ Yuri Miguel Macedo \\ ${ }^{1}$ Universidade Federal Fluminense - yurimacedo@id.uff.br
}

RESUMO: A presente pesquisa tem por finalidade promover uma reflexão sobre como a arte pode contribuir para a construção e a divulgação da identidade surda ao evidenciar sua importância para a vida dos surdos e sua comunidade. Neste trabalho empregou-se a abordagem qualitativa cujo levantamento bibliográfico nos levou a utilizar textos de autores que abordam a arte surda como: Anjos (2008), Caldas (2006); e a surdez como: Nakagawa (2012), Perlin (2008), Quadros (2004), Skliar (1998), Strobel (2008), dentre outros autores que possuem pesquisas com temas que colaboraram para a elaboração deste artigo cuja finalidade é promover reflexões acerca da importância da arte surda para os alunos surdos e a Comunidade Surda, ao passo que tentamos identificar a existência de carências que envolvem o uso dessa arte no cotidiano do surdo, assim como sua relevância no auxílio para o processo de inclusão dos surdos na sociedade e seus benefícios, tanto para os surdos quanto para sua comunidade e afins.

Palavras-Chave: Arte. Arte surda. Comunidade Surda. Identidade Surda.

ABSTRACT: This research aims to promote a reflection on how art can contribute to the construction and dissemination of deaf identity by highlighting its importance for the lives of deaf people and their community. In this work, a qualitative approach was used, whose bibliographical survey led us to use texts by authors who address deaf art, such as: Anjos (2008), Caldas (2006); and deafness as: Nakagawa (2012), Perlin (2008), Quadros (2004), Skliar (1998), Strobel (2008), among other authors who have research on themes that collaborated for the preparation of this article, whose purpose is to promote reflection about the importance of deaf art for deaf students and the Deaf Community, while we try to identify the existence of needs that involve the use of this art in the daily life of the deaf, as well as its relevance in helping the process of inclusion of deaf people in society and its benefits, both for the deaf and for their community and the like.

Keywords: Art. Deaf art. Deaf Community. Deaf Identity. 


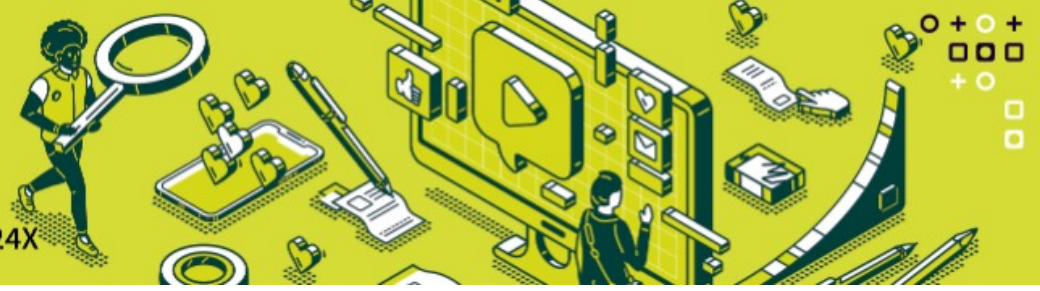

\section{Prologuemos}

O surdo ${ }^{1}$ na sociedade, muitas vezes, é desprovido de seus direitos sociais, culturais e educacionais. O tema abordado pretende ressaltar a importância do desenvolvimento artístico para os surdos, por ser uma ferramenta de grande relevância que estimula o campo visual, tende a estender-se à identidade cultural, educacional e auxilia no processo de inclusão na sociedade. $O$ processo de inclusão sugere que haja formação e aceitação da diversidade e que permita o acesso às oportunidades. A arte é um fator considerável nesse contexto, pois o aluno surdo, no contato com a arte, é desafiado a criar e a expressar sua imaginação exercendo uma linguagem artística que poderá facilitar a divulgação de sua história, suas crenças, e também trabalhar na interpretação de acontecimentos cotidianos.

Tentamos, com esta pesquisa, trazer uma reflexão acerca da arte surda, estabelecendo conexões entre aspectos da cultura surda e as discussões sobre cultura visual. O entendimento sobre a arte surda pode ser enriquecido ao se estabelecer um diálogo ente os estudos culturais surdos e estudos da cultura visual, pois as reflexões proporcionadas pela cultura visual tornarse-ão mais compreensíveis diante de determinados aspectos culturais que são evidenciados nas produções artísticas de estudantes surdos.

Vale ressaltar que existe uma lacuna muito grande entre a prática de artes e o público especial. Os materiais didáticos e publicação de livros no Brasil que abordam a arte com pessoas surdas ou que tragam em seu conteúdo o ensino de artes no contexto da inclusão são pouquíssimos. Mesmo assim, tentaremos discorrer sobre como a arte pode contribuir para a construção e a exposição da identidade da cultura surda e despertar o conhecimento da arte surda de forma que possa auxiliar no processo de conexão do surdo em sua identidade e cidadania em meio à cultura ouvinte.

\section{POR ONDE OUVIMOS E FALAMOS}

O tema aqui abordado é de suma importância, diante do fato de que existem artistas surdos, em diferentes contextos, que se expressam com a Língua de Sinais, tais como: atores, poetas, artistas plásticos, contadores de história, músicos, dentre outras modalidades artísticas cujas artes são relevantes. Sua inclusão no viés educativo para alunos surdos poderia colaborar em grande escala no processo de inclusão, com o intuito de que as diversas formas de expressão sejam apresentadas e incentivadas no ambiente escolar.

Para Strobel (2008, p. 66) "o artista surdo cria a arte para que o mundo saiba o que pensa, para divulgar as crenças do povo surdo, para explorar novas formas de "olhar" e interpretar a cultura surda", e assim imaginamos que a inclusão poderá ganhar mais força, com uma expansão de artes cuja cultura surda possa se mostrar e fazer-se conhecer através da exposição de suas vidas, suas lutas, e sua história diante da cultura ouvinte.

A aceitação da diversidade permite o acesso às oportunidades, e a arte é um fator considerável, pois o aluno surdo no contato com a arte é desafiado a expressar a imaginação exercendo uma linguagem artística que poderá facilitar na divulgação de sua história.

A metodologia adotada para o desenvolvimento deste trabalho consiste na pesquisa bibliográfica com abordagem qualitativa, na qual estudamos diversos autores que abordam a

${ }^{1}$ Indivíduo que ouve pouco ou não ouve, em consequência de uma perturbação auditiva congénita ou adquirida. 


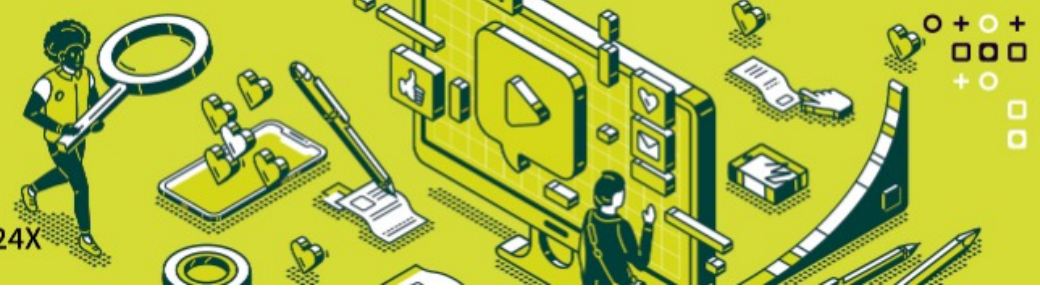

arte surda, dentre os autores pesquisados: Ronice Muller de Quadros, Gladis Perlin e colaboradores em Estudos Surdos II, o livro Cultura Surda e Libras com Organização de Maura Corcini Lopes e colaboradores, Surdos: Qual escola? com organização de Nídia Regina Limeira de Sá; e alguns teóricos que defendem o uso da arte surda como Campello (2008) e Montoan (1997), e outros pesquisadores sobre a surdez.

Contudo, tentamos entender como acontece o processo de integração nas escolas, buscando estabelecer diálogos e/ou aproximações dos alunos surdos com o mundo da arte. Tentamos identificar a carência da arte surda nas escolas, e mostrar nesta pesquisa a importância das artes para os surdos, desenvolvendo discussões sobre a importância da arte nas escolas e a importância da arte surda como auxílio para a inclusão dos surdos na sociedade.

\section{ARTE SURDA X CULTURA SURDA}

No texto "Arte surda: interfaces entre cultura surda e cultura visual" de Neto, Jesus e Gomes (2017) encontramos a informação que no Brasil existe uma carência em estudos que tratem da constituição histórica da arte surda em território brasileiro e que temos Karin Strobel como pesquisadora brasileira surda que possui textos publicados com temas voltados à arte surda e as criações artísticas do povo surdo como manifestações de suas lutas, ideologias, história e cultura, trazendo sempre em evidência elementos da cultura surda como a língua de sinais e suas experiências visuais surdas.

Para Cruz (2016, p. 44) "A expressão artística é uma linguagem da qual o surdo faz uso e isso não depende necessariamente do sucesso de sua escolarização", dito isto, entendemos que os surdos tendem a se expressar através da arte desde que estes sejam apresentados aos estudos artísticos, até porque o surdo tem como foco o campo visual, o que torna a expressão artística algo que possa complementá-los.

Além das artes visuais, as formas artísticas utilizadas pelos surdos se estendem aos mais diversos meios artísticos. Embora Cruz (2016, p, 52) apud Strobel (2013, p. 88) não considere a música como parte da cultura surda, existem surdos músicos que compõem através da percussão do corpo e outras performances em que os surdos utilizam a música como manifestação de sua cultura, assim também como outras amostras artísticas: o teatro, a dança, artes plásticas, escultura, artes cênicas, produção de vídeos, poesia, mágicos surdos. O campo é vasto, basta apenas que the mostremos as possibilidades para que os mesmos possam escolher a que mais Ihe agrada para se expressar.

Entre a cultura surda e a arte surda existe a cultura visual que foi desenvolvida no princípio da existência humana, pois os recursos visuais são tudo o que se possa utilizar para compartilhar algum tipo de idéia através do campo visual. Segundo Neto, Jesus e Gomes (2017) tais exemplos estão nas pinturas rupestres registradas em sítios arqueológicos. Atualmente, o maior difusor desta cultura é o mundo contemporâneo com tecnologias e mídias digitais que constantemente vem inovando e criando métodos e artefatos que disseminem produções envolvendo o campo visual.

Os estudos sobre a cultura visual se desenvolvem com o intuito de compreender como, na atualidade, os aparatos tecnológicos são utilizados diante das necessidades comunicativas que envolvem o campo visual, tais como: vídeos, fotografias, imagens, artes visuais, dentre outros. Sobre a cultura surda, Strobel dá seu parecer dizendo que: 


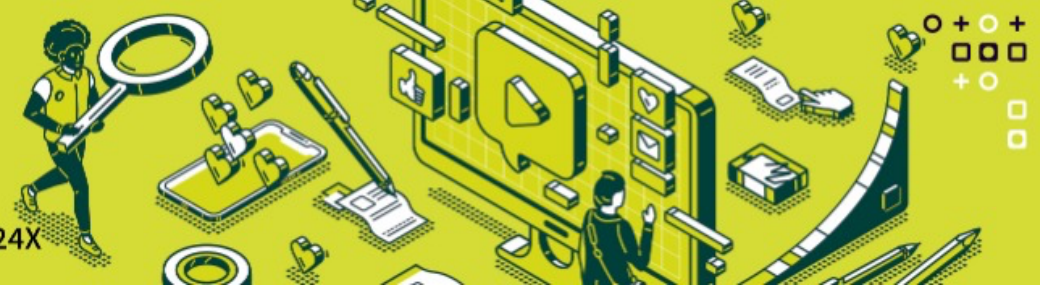

Cultura surda é o jeito de o sujeito surdo entender o mundo e de modificá-lo a fim de torná-lo acessível e habitável, ajustando-o com as suas percepções visuais, que contribuem para a definição das identidades surdas e das "almas" das comunidades surdas. Isto significa que abrange a língua, as ideias, as crenças, os costumes e os hábitos do povo surdo. (STROBEL, 2009, p. 22)

Como podemos perceber, a cultura surda é constituída do sujeito surdo que tem como foco de sua atenção o campo visual. Por isso, a cultura visual tem grande importância, pois através dela é que a cultura surda pode se expressar melhor, conforme se adquire as habilidades de utilizar tecnologias e mídias que possam colaborar para que os surdos possam se manifestar diante de suas percepções visuais juntamente à sua língua, ideias e histórias.

Tendo em vista que as experiências do povo surdo são construídas visualmente, pois sua visão substitui a audição, e, desta forma, a experiência visual faz-se necessária da utilização de uma língua visual, ou seja, a Língua de Sinais, que é a maneira pela qual os surdos se expressam, conhecem o mundo e adentram nos vários meios de conhecimento.

A Língua de Sinais é uma língua visual-espacial articulada através das mãos, das expressões faciais e do corpo, podendo ser captada visualmente e através do tato por surdos-cegos. No Brasil, chamada de Língua de Sinais Brasileira (Libras):

São línguas que são utilizadas pelas comunidades surdas. As línguas de sinais apresentam as propriedades específicas das línguas naturais, sendo, portanto, reconhecidas enquanto línguas pela Lingüística. As línguas de sinais são visuais-espaciais captando as experiências visuais das pessoas surdas. (QUADROS, 2004, p. 8)

Em 24 de abril de 2002 a Lei Federal $n^{\circ} 10.436$ foi aprovada e a Libras passou a ser reconhecida como língua oficial das comunidades surdas.

[...] entendemos que a comunidade surda de fato não é só de sujeitos surdos, há também sujeitos ouvintes - membros de família, intérpretes, professores, amigos e outros - que participam e compartilham os mesmos interesses em comuns em uma determinada localização. (...) Em que lugares? Geralmente em associação de surdos, federações de surdos, igrejas e outros. (STROBEL, 2008, p. 29)

Segundo Strobel (2008), na comunidade surda existem alguns artefatos culturais que são muito importantes, dentre eles, as artes visuais, a experiência visual, a Língua de Sinais, a família, a literatura surda, a vida social e esportiva, a política e os materiais. "[...] o conceito "artefatos" não se referem apenas a materialismos culturais, mas àquilo que na cultura constitui produções do sujeito que tem seu próprio modo de ser, ver, entender e transformar o mundo". STROBEL (2008, p.37)

A arte surda é o artefato da cultura surda em que podem expressar seus sentimentos, seus ideais, suas lutas, sua história, sua identidade cultural, e ainda fazer um diálogo entre os estudos da cultura surda e da cultura visual. A arte surda também é utilizada como instrumento de denúncia contra práticas que foram frequentes no passado da cultura surda, nas quais ouvintes atribuíam práticas ouvintistas aos surdos, forçando-os a falar através do método médicoterapêutico e induzindo-os ao uso de próteses auditivas além da discriminação que sofriam, tendo que abandonar sua cultura, identidade surda e se submeterem a uma etnocêntrica ouvintista, sendo obrigados a imitar os ouvintes. 


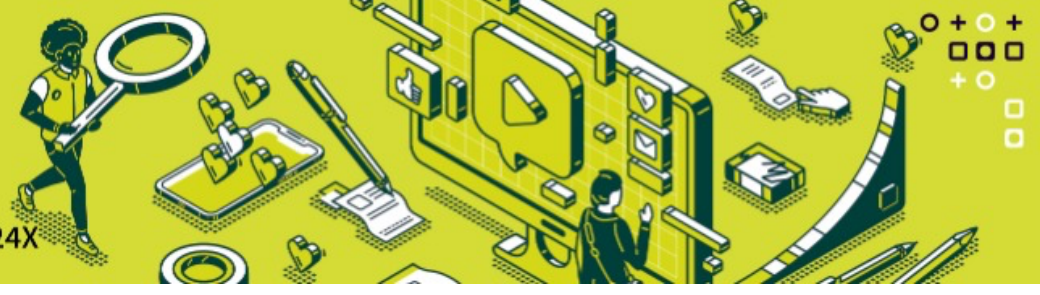

Hoje em dia a tecnologia vem sendo de grande valia para a população surda por possibilitar trocas comunicativas através de registros, acesso a informações e produções culturais que se dinamizam, mesmo que geograficamente distantes há um fortalecimento de vínculos na comunidade surda.

Mensagens de texto trocadas entre telemóveis, dispositivos de captura e partilha de vídeos que permitem conversas à distância (em língua gestual) e possibilitam o registro e a promoção de produções culturais, redes sociais virtuais que congregam e fomentam o compartilhar de ideias, ideais, notícias, histórias, ficheiros, entre outros novos suportes que mediam os processos informacionais e comunicativos entre surdos e surdos/ ouvintes dão novos poderes de articulação e mobilização a esses grupos. (NAKAGAWA, 2012, p. 33-34)

Segundo Nakagawa (2012), com os aparatos tecnológicos surdos podem divulgar-se, empoderar-se, e reconfigurar-se ao passo que ganham novas fronteiras a partir da internet como uma interface de afirmação identitária, utilizando o ambiente virtual para reverberar por meio de vídeos, imagens, encontros e discussões virtuais em tempo real que tratam de novos discursos sobre alteridade.

O artefato experiência visual vem da própria cultura surda, a cultura visual, com suas experiências pessoais, a partir da língua viso-espacial, as expressões faciais e corporais. É a percepção do mundo através dos olhos.

A marca principal do artefato linguístico é a Língua de Sinais, que é um dos principais marcadores culturais da cultura surda, composta por níveis linguísticos: fonologia, morfologia, sintaxe e semântica. Tem sua própria gramática, não é universal, pois cada país tem sua Língua de Sinais, elas são desenvolvidas a partir das necessidades comunicativas e culturais de cada lugar de origem.

O artefato literatura surda pode ser dividida em três categorias: tradução (obras de autores ouvintes traduzidas para a Língua de Sinais), adaptação (recriação de obras clássicas) e criação (produção de autores surdos), e é nela que a SignWriting ou Escrita de Sinais se encaixa. Ela vem sendo mais difundida ultimamente e utilizada em escolas de surdos para a produção de textos escritos e na tradução de textos e historinhas infantis:

[...] o sistema pode representar línguas de sinais de um modo gráfico esquemático que funciona como um sistema de escrita alfabético, em que as unidades gráficas fundamentais representam unidades gestuais fundamentais, suas propriedades e relações. O SignWriting pode registrar qualquer Língua de Sinais do mundo sem passar pela tradução da língua falada. Cada Língua de Sinais vai adaptá-lo a sua própria ortografia. (STUMPF, 2007, p. 50)

Outros artefatos culturais dos surdos são a família e materiais. As práticas surdas no convívio familiar são mais facilmente internalizadas, em um processo contínuo de aprendizado e ajustamentos, pois o ambiente familiar representa um espaço de partilha linguística, onde adultos e crianças podem compartilhar experiências, conversar, trocar conselhos e conhecimentos diários, sem obstáculos comunicativos.

$\mathrm{Na}$ casa dos surdos, muitos aparelhos podem ser encontrados para facilitar a vida diária, como transformar avisos sonoros em sinais luminosos ou vibratórios, campainha luminosa, 


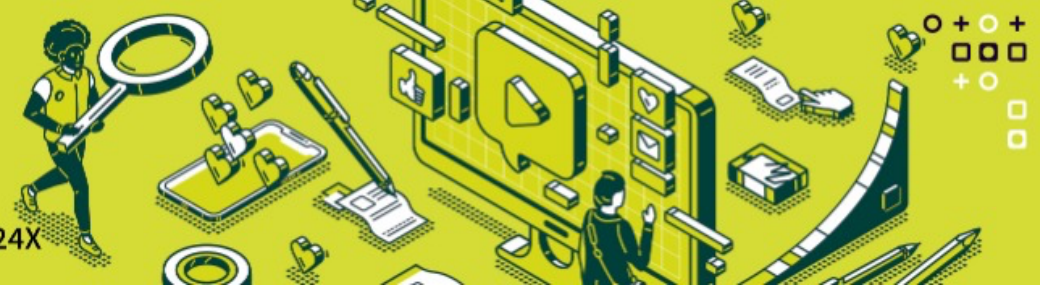

despertadores vibratórios, babá eletrônica por avisos luminoso (tecnologia que reconhece o choro e aciona avisos luminosos), ou, babá eletrônica como pulseira vibratória (capta apenas o choro do bebê alertando os pais surdos), televisores com legenda em Libras, aplicativos com traduções para Libras, e muitos outros materiais que servem de artefatos culturais para os surdos.

Um aplicativo bastante conhecido é o ProDeaf que é capaz de traduzir texto e voz do Português para Libras (Língua Brasileira de Sinais) com o objetivo de permitir a comunicação entre surdos e ouvintes. A Suite VLibras também é uma ferramenta utilizada para a tradução automática de conteúdos digitais para Libras em código aberto e distribuição livre, desenvolvido pelo Lavid Laboratório de Aplicações de Vídeo Digital da Universidade Federal da Paraíba em João Pessoa. Outro aplicativo conhecido é o Hand Talk, um software que traduz rapidamente mensagens em português para Libras, e atualmente foi premiado no Desafio Google de Impacto em Inteligência Artificial.

$\mathrm{O}$ artefato político refere-se às leis e a luta pelos direitos das pessoas surdas, protestos a favor de suas ideologias e uso da própria língua, e suas conquistas. $O$ artefato que se refere à vida social e esportiva do povo surdo, aos acontecimentos culturais e vida em sociedade como festas, casamentos entre surdos, lares e atividades ligadas às associações de surdos, eventos esportivos dentre outros.

\section{O ENSINO DE ARTE PARA SURDOS}

Em maio de 2016 foi promulgada a Lei № 13.278/2016 que altera a Lei de Diretrizes e Bases da Educação Nacional Lei no 9.394/1996 (LDB) que inclui artes visuais, artes cênicas, dança e música no ensino de artes nos ensinos infantil, fundamental e médio. Em agosto de 2008 tornaram-se obrigatórias com o advento a Lei Federal 11.1769.

Apesar do ensino de artes estar implantada pela LDB e no BNCC (Banco Nacional Comum Curricular), ainda deixa a desejar na qualidade, pois, segundo Caldas (2006), pesquisadora surda, é necessário que haja uma melhor compreensão acerca dos pintores famosos e mesmo nos espaços culturais como museus, exposições, galerias, bienais, que carecem de interpretes ou mediadores que tenham conhecimento da Libras para que os surdos tenham acesso às informações sobre o que estão vendo, podendo fazer conexões com experiências pessoais anteriores. Há ainda a falta de legendas ou de acesso ao intérprete em documentários televisivos e até em cinemas.

A escola deve ser o espaço na qual possa fazer este contato com o mundo da arte. Caldas (2006) nos elucida que, "o entendimento ou não de qualquer obra está relacionado com o contato que o sujeito tem com a arte" (Caldas, 2006, p. 39).

A arte tem essa função de provocar, estimular, e como a autora Caldas (2006) ressalta através de Eisner (1995), é de suma importância a aprendizagem compromissada para o acesso às ideias, habilidades e produtos que formam o patrimônio cultural, pois serão convertidos em repertório intelectual e estético, desenvolvendo uma inteligência qualitativa conforme desafia a criança a apreciar diferentes linguagens estéticas. No trecho a seguir Caldas (2006) expõe seus ideais expressando politicamente o direito ao acesso, participação e profissionalização do surdo em relação à arte: 


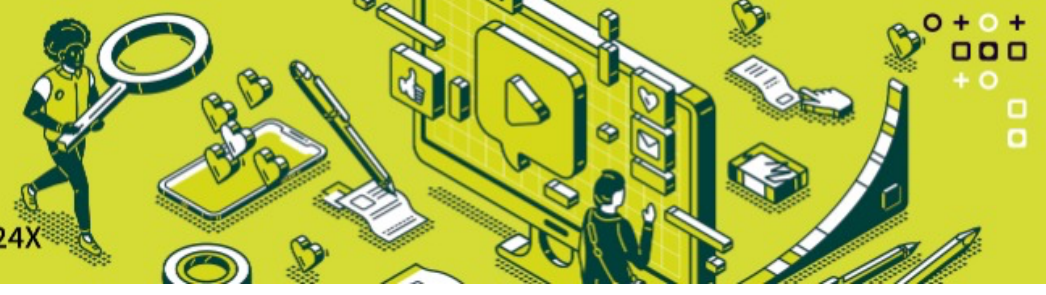

[...] os alunos surdos precisam de contato com a arte surda, tal como é mostrada na história, no dia-a-dia do surdo com sua produção de significados; levar os surdos ao contato com artistas surdos e com a arte surda através de fotos, vídeos, pinturas, esculturas, teatro, considerar que os olhos, as mãos, a expressão corporal são sinais referenciais para os surdos, despertar os surdos para a arte, a fim de que possam expressar sua identidade surda através da mesma; ver a arte surda como forma de significação que produz certas características determinadas para a diferença e as construções históricas e culturais; colocar a pergunta: por que vivemos num complexo tão desumano em relação à arte surda?; considerar que há artistas surdos em diferentes contextos como atores, poetas em Língua de Sinais, pintores, mágicos, escultores, contadores de histórias e outros, tais como cineastas; adotar como estratégia relevante para arte nas escolas a discussão com os alunos sobre como criar a arte surda; incentivar o teatro, a poesia, a pintura e pesquisas na história, na comunidade surda e outros; artistas surdos ou debates na comunidade surda sobre a arte seriam bem vindos para incentivar os alunos "desgastados" pela exclusão da arte nas escolas de surdos; observar que o uso das imagens sobre o surdo na sala de aula precisa conter algo dos surdos; um bom ponto de pesquisa está na Internet, onde há sites de surdos que trazem imagens autênticas de surdos; considerar necessário o conhecimento da arte e expressão surda por parte dos professores, que precisam conhecer a arte surda para que o aluno surdo possa desenvolver sua criatividade e não se envergonhe ou esconda sua arte; reconhecer que alguns surdos têm dons muito próprios para a arte de expressão corporal e ela deve ser incentivada pela família, escola ou associação de surdos; repensar e discutir a arte surda no que ela representa em suas limitações políticas; encorajar os surdos para a busca de significados que expressem a/s cultura/s surda/s; assegurar que a arte a ser usada na escola não se resuma a pintar desenhos "pré-feitos por professores", ou "cantar" músicas que são destituídas de significado para a cultura surda; considerar que, em nossas escolas, existem pequenas ou mínimas referências ou quase nada de iniciação à arte surda. (CALDA, 2006, p. 42-43)

A autora ainda nos traz a importância para o teatro da linguagem corporal por expressar as emoções e sentimentos, por isso deve estar conectada e integrada com a linguagem, pois quando a pessoa surda não tem acesso à sua língua nativa desde cedo, não obtêm segurança.

O decreto $\mathrm{n}$ o 5.626 de 22 de dezembro de 2005 institui o ensino aos surdos na Língua de Sinais, a oficialização da Língua de Sinais em nível nacional já havia sido garantida pelo Congresso Nacional em 1996 através do decreto no 9.394, de 20 de dezembro de 1996.

Quanto à acessibilidade garantida aos surdos, referente aos meios essenciais de participação social, foi implantada a Lei no 10.098, de 19 de dezembro de 2000. O Artigo 17 desta Lei explica que o Poder Público deve promover a eliminação de barreiras na comunicação e estabelecer mecanismos e alternativas técnicas que tornem acessíveis os sistemas de comunicação, garantindo o direito de acesso à informação, comunicação, trabalho, educação, transporte, cultura, esporte e lazer.

A Lei Federal $n^{\circ} 10.436$, no Art. 4ํㅡ, diz os sistemas educacionais estaduais, municipais e do Distrito Federal devem garantir a inclusão nos cursos de formação de Educação Especial, de Fonoaudiologia e de Magistério, em seus níveis médio e superior, o ensino da Libras, como parte integrante do BNCC. 


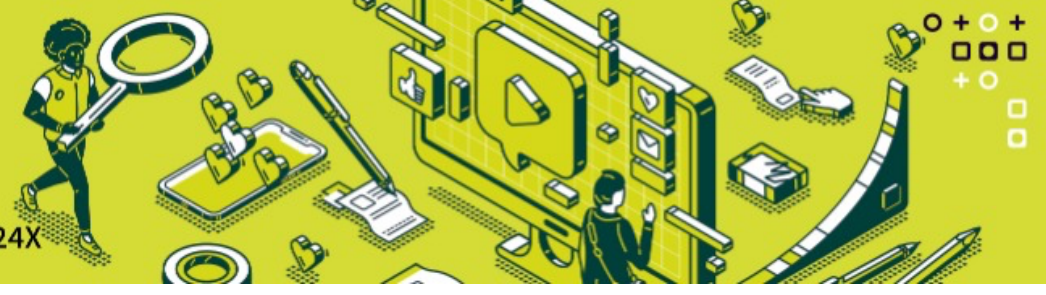

O artigo 27 da Declaração Universal dos Direitos humanos (ONU, 1948) diz que: "[...] toda pessoa tem o direito de tomar parte livremente na vida cultural da comunidade, de fruir as artes e de participar no progresso científico e nos benefícios que deste resultam"

Segundo a Portaria no 1.679, de 1999 e Resolução CNE/CEB no 02/200, os surdos podem contar com a presença de intérpretes em atendimento especializado (ECA, LDB, Plano Nacional de Educação - Lei no 10.172 de 2001), adaptações curriculares (Resolução CNE/CEB no 02/2001), entre outras disposições. Sendo assim, fica evidente que, após tanto tempo, algumas leis ainda não estão em vigor, ou pelo menos, não em todos os lugares, tendo em vista que:

Segundo o censo realizado em 2010 pelo instituto Brasileiro de Geografia e Estatísticas - IBGE, 9,8 milhões de brasileiro possuem deficiência auditiva, o que representa $5,2 \%$ da população brasileira. Deste total 2,6 milhões são surdos e 7,2 milhões apresentam grande dificuldade para ouvir. Já, de acordo com a Organização Mundial de Saúde (2011) 28 milhões de brasileiros possuem algum tipo de problema auditivo, o que revela um quadro no qual $14,8 \%$ do total de 190 milhões de brasileiros, possuem problemas ligados à audição. (IBGE, 2010)

Ou seja, devido à quantidade de surdo no Brasil, as leis deveriam estar em vigor desde seu decreto e essa falha no cumprimento das leis recai sobre os surdos que são os principais a serem prejudicados, pois se não Ihes é garantida a educação devida, que, de acordo com estudiosos e os próprios surdos, é a educação bilíngüe por valorizar a Língua de Sinais como primeira língua, a língua materna dos surdos. A falta do desenvolvimento lingüístico implica no desenvolvimento de qualquer disciplina, seja ela matemática, história, Libras, Português, geografia, artes etc.

Perlin e Strobel (2008) sobre a cultura surda e as narrativas diante de seus ideais para a comunidade surda diz:

Primeiramente temos narrativas pedagógicas onde enfatiza o jeito surdo de ensinar, onde apela por estratégias de ensino visuais, transmissão de conhecimentos em Língua de Sinais, com presença de professores surdos; as narrativas da política pedem outras considerações em ralação às leis, métodos de educação, saúde; as narrativas lingüísticas que apelam pela diferença e autenticidade de nossa Língua de Sinais; as narrativas da identidade remetem a que o sujeito subjetiva e simplesmente se reconheça surdo; as narrativas das artes como literatura, teatro, piadas, bem como na poesia, que, como disse Raquel Sutton Spencer (2005), enfatizam e celebram a beleza e a complexidade de nossa Língua de Sinais, pedem respeito a nossa diferença enquanto surdos, constroem relacionamentos sociais e nos defendem das ameaças à nossa identidade, transmitem valores culturais motivando a troca de experiências sobre o ser surdos, celebram o sucesso do surdo e do povo surdo. Estas narrativas, sem pretender esgotar sobre 0 assunto remetem para a riqueza e expressividade da cultura surda. (Perlin e Strobel, 2008, pag. 70)

Como podemos perceber, as narrativas contidas nas modalidades artísticas dão ênfase e celebram a beleza e complexidade da Libras e na própria exaltação artística pode-se perceber o que ela pretende transmitir por conter na arte todos os aparatos de expressão de sentimentos, tendo em vista que o campo visual já é de característica da língua dos surdos, o que faz valorizar mais ainda essa ligação entre eles através dessa tríade: cultura surda, cultura visual e arte surda. 


\subsection{ARTE SURDA}

A arte é uma ação produtiva que está ligada diretamente ao social e ao cultural, pois acarretam representações de ações vivenciadas em ambas. As Artes Surdas, sejam elas, na área da Literatura, teatro, artes plásticas, dança, música, cinema, design, etc. trazem às telas, aos palcos, ao mundo, novas formas de olhar, pensar, sentir e expressar a partir da representação de suas próprias experiências nesses meios.

Segundo Nakagawa (2012, p. 71) a Arte Surda define-se "como aquela que, por meio de diferentes suportes, resgata, retrata e evidencia - direta ou indiretamente, mas de maneira apreensível - traços das experiências Surdas".

Logo, as Artes Surdas diferenciam-se de obras produzidas por surdos, por estas poder tratar de vários temas, estilos e escolas, enquanto a primeira é caracterizada assim por seu conteúdo expresso e não a identidade de quem a produziu. Para Nakagawa (2012):

Em 1989, proeminentes artistas Surdos reuniram-se no festival Deaf Way75 e lançaram um manifesto que serviu de base para se reconceituar a chamadas Artes Surdas. Nesse texto, lançam o termo De'VIA (Deaf View/Image Art) para determinar um tipo de arte em que estiverem representadas as percepções e experiências Surdas. (Nakagawa, 2012, p. 71)

Este festival é um dos mais importantes festivais de cultura surda do mundo e acontece em Washington D.C. De acordo com a compreensão De'VIA, artistas ouvintes (ligados ao mundo Surdo, sejam filhos de pais Surdos, irmãos, profissionais, professores, etc) também podem criar a Arte Surda, porém esta informação gerou um pouco de desconforto para alguns surdos. As Artes Surdas para o De'VIA prezam pela riqueza do conteúdo expresso, primor estético e importância simbológica que remetem às lutas, deixando sobressair toda sua complexidade, e, sobretudo, a qualidade da obra é avaliada em sua amplitude estética, conceitual, metafórica etc. A autora surda Anjos (2008, p. 5) diz que:

Fazer a arte tornar-se conhecimento é fundamental para que as pessoas descubram a expressão e a valorização de si. Fazer arte é alfabetizar-se nas linguagens da arte. $E$ através deste entender diferentes culturas e confrontálas, unificando-as ou conhecendo-as. (ANJOS, 2008, p. 5)

Destaca que fez Graduação de Artes Visuais e relata que foi na comunidade surda que:

[...] percebi os primeiros resquícios da existência de uma arte surda, como objeto de uma representação social, que utilizava recursos, tais como: a utilização das mãos e corpo para declamar poesia, o teatro sinalizado, pinturas onde o elemento principal eram as mãos. (ANJOS 2008, p. 5)

Na DB é assegurado "O ensino da arte, especialmente em suas expressões regionais, constituirá componente curricular obrigatório da educação básica". É interessante que os surdos tenham conhecimento tanto das artes quanto dos artistas surdos que representam sua cultura para que assim valorizem seus pares e estimulam novas formas de representações artísticas, contribuindo para o resgate da história do povo surdo, a elevação da autoestima e na reconstrução e divulgação da identidade surda. "Apreciar a arte é construir novos olhares, é compreender os 


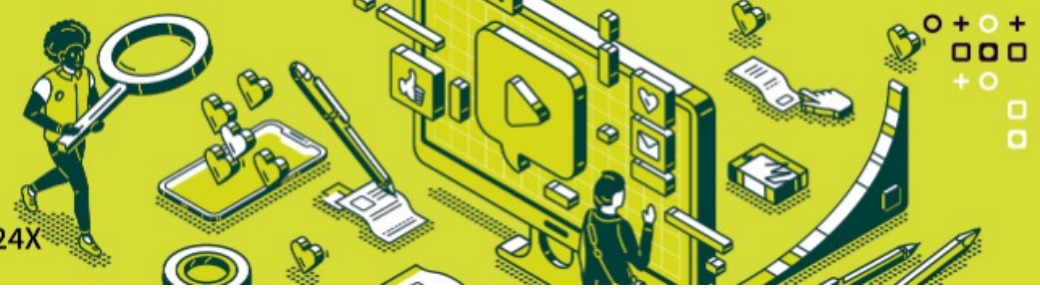

diferentes significados expostos. É saber que a arte é mediada pelos conhecimentos, revelando uma cultura específica onde o autor ou artista está inserido". (ANJOS, 2008, p. 13)

\subsection{LITERATURA SURDA}

A Literatura surda abrange todas as produções linguísticas que se comunicam através da língua visual-espacial, e consiste em três categorias: Obras de autores ouvintes traduzidas para a Língua de Sinais, adaptação de obras clássicas, e criação de autores surdos.

A Escrita em SignWriting é outra forma de registro da Literatura Surda que possibilita que textos impressos circulem em espaços e tempos diferentes. As primeiras produções no Brasil foram as releituras das histórias infantis Rapunzel e Cinderela, intituladas como Rapunzel surda e Cinderela surda (dos autores brasileiros Caroline Hessel, Fabiano Rosa e Lodenir Becker Karnopp), as obras foram resultados de uma pesquisa que eles desenvolveram e posteriormente publicaram como "Letramento e surdez: uma abordagem lingüística e cultural", que tinha como objetivo principal divulgar a língua escrita de sinais e incentivar as escolas a implantá-la como disciplina. A SignWriting foi introduzida no Brasil em 1996 por Marianne Rossi Stumpf (primeira surda a escrever os sinais da LIBRAS) e com a ajuda do Dr. Antônio Carlos a Rocha Costa traduziram do português para a escrita de sinais o primeiro texto escrito em língua de sinais no Brasil: Uma menina chamada Kauana. Outras produções: O Menino, o Pastor e o Lobo, Davi, Noé, ambas com autoria de Sérgio Silva Ribeiro, publicadas no livro intitulado "Textos em Libras".

Livros com grande importância para a Surdez são os escritos por Helen Keller (1952) autora Surda-cega, que publicou: "Optimismo-um ensaio, "A Canção do Muro de Pedra”, "O Mundo em que Vivo", "Lutando Contra as Trevas", "A Minha Vida de Mulher", "Paz no Crepúsculo", "Dedicação de Uma Vida", "A Porta Aberta", "A História da minha vida”, "Minha Religião".

A Literatura Surda também é encontrada em forma de romance como o livro "Mamadu, o herói surdo", da autora surda portuguesa Marta Morgado e "O vôo da gaivota" da autora surda francesa Emmanuelle Laborit.

A oferta de Livros sobre a surdez vem aumentando conforme a comunidade surda vem sendo mais reconhecida, autores surdos brasileiros contribuem para essa expansão da literatura surda, inclusive nas universidades, colaborando para novos estudos no ramo da surdez e fortalecendo assim a representação dos surdos no campo literário como: Jorge Sérgio L. Guimarães, surdo carioca, com o livro autobiográfico "Até onde vai o Surdo"; Olindina Coelho Possídio, surda pernambucana, com o livro "No meu silêncio: ouvi e vivi"; Shirley Vilhalva com "Recortes de uma vida: Descobrindo o Amanhã", "Despertar do Silêncio" e "Índios Surdos: mapeamento das línguas de sinais do Mato Grosso do Sul".

Para que os livros circulem e alcancem seus leitores é necessário alguém que os publique. A editora que mais promove a produção literária sobre a surdez no Brasil é a Arara Azul, que publica tanto materiais impressos quanto em suporte audiovisuais, tendo uma série de títulos com narrativas em língua portuguesa e em Língua de Sinais, ela produz materiais técnicos, acadêmicos literários e ainda possui um Centro Virtual de Cultura Surda que tem por finalidade ofertar formações, cursos e ações sobre a surdez.

No Brasil também existe A Revista Arqueiro, um periódico especializado em surdez e educação de surdos do país publicada semestralmente pelo Instituto Nacional de Educação de Surdos 
(INES/MEC).E ainda para quem gosta de tirinhas ilustradas e Cartoons temos no Brasil as tiras de Palavras Inaudíveis com autoria de Diogo Madeira, e Tikinho como é conhecido o desenhista Lucas Ramom Alves, ambos são surdos e abordam sobre a surdez em suas publicações.

\subsection{POESIA}

A poesia em línguas de sinais e gestuais é uma forma de alimentar e embelezar o movimento do ser surdo, reelaborando em sinais poéticos as experiências dos surdos. Para Nakagawa (2012, p.73):

Os poemas em L.S são, para muitos, o hors concours da sofisticação estética e gramatical no uso das línguas gestuais. As expressões faciais, a cadência do corpo, o ritmo compassado dos movimentos, a rima nas mãos, o uso de uma forma elevada da língua (o "sinal arte"): uma boa poesia gestual encanta não só por sua força cênica e sua intensidade performática como também pelas ofertas vocabulares (espaciais-visuais) e pela beleza dos recursos linguísticos (e extra-linguísticos) utilizados. (NAKAGAWA, 2012, P.73)

Em uma pesquisa feita por Rachel Sutton-Spence (2014), encontramos evidências dos benefícios da poesia sinalizada para crianças surdas. A autora aborda sobre um poeta americano surdo e professor, Robert Panara, que em 1979 defendia "o ensino de poesia escrita para a criança surda através da intermediação da língua de sinais" (PANARA, 1979, p. 825), no qual o mesmo diz que ensinar poesia:

[...] Ajuda a estimular criatividade e expressão pessoal, e encoraja o desenvolvimento das faculdades intelectuais do estudante - imaginação, pensamento e interpretação [...]. Assim como na exposição às artes dramáticas ou à dança, faz o estudante reagir emocionalmente e sensitivamente à arte de expressão [...]. Através da linguagem da poesia os estudantes podem aprender a perceber como o lugar comum é feito parecer incomum, como palavras antigas podem ser expressas com frescor, originalidade e beleza (apud PANARA, 1979, p. 825).

Logo, os benefícios do ensino de poesia para crianças surdas são de grande relevância, tais quais as demais artes, e tão importantes quanto ao ensino para crianças ouvintes, pois ambas estimulam a criatividade, principalmente quanto ao uso da língua de sinais.

Ver a poesia em língua de sinais abre uma dimensão completamente nova em que a beleza e os desafios da forma poética ainda estão presentes, mas as barreiras da língua são removidas. $O$ impacto da exposição à poesia sinalizada não pode ser subestimado (SUTTON-SPENCE, 2014, p. 118).

Há evidências de que a poesia sinalizada pode ajudar bastante os alunos surdos a apreciar, se desenvolver criativamente e envolver-se com a poesia escrita também, e isso pode ter grande utilidade no ensino da L2.

Segundo Sutton-Spence (2014), a poesia sinalizada é importante para a cultura surda, por ser uma maneira de expressar experiências pessoais, sejam elas positivas ou negativas, mas sempre tem seu valor, pois o importante é mostrar como se deu a história de experiências e opressões da comunidade surda. Conforme os alunos surdos passam a compreender a beleza, facilidade e 


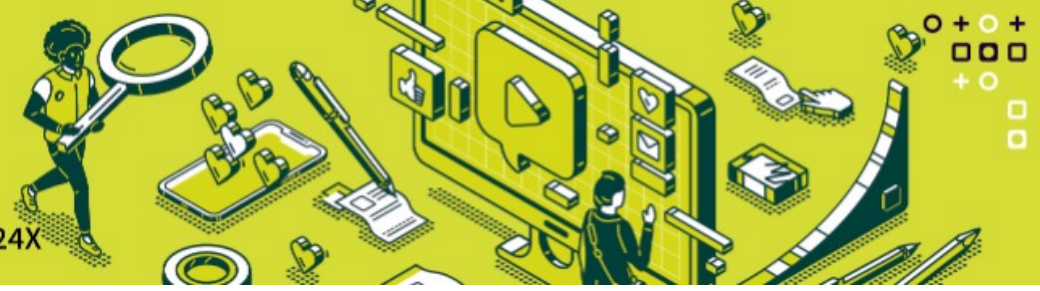

benefícios da poesia sinalizada, ela poderá ser a forma de expressão utilizada para expor diversos assuntos que envolvam seus sentimentos, experiências e medos.

No Brasil, Nelson Pimenta é o poeta e ator mais conhecido; Levent Beskardès na França; e Peter Cook nos Estados Unidos. Outros poetas brasileiros surdos: Rosani Suzini, que também é professora formada em Letras e tem pós em Libras e Letras/Libras; e Ana Luiza Caldas, que também é professora.

\subsection{MUSICALIDADE}

Atualmente os surdos vêm conquistando mais espaços em meio à sociedade, uma das questões refere-se ao surdo ter acesso à música. Antigamente acreditava-se que seria inviável para o surdo, porém atualmente sabemos que as ondas sonoras são sentidas pelo corpo que capta as vibrações e através delas, podem transmitir vários tipos de sensações, que podem elevar a autoestima, e melhorar a compreensão do mundo. Segundo Silva e Rocha (2019), existem surdos que sentem a música e outros que não sentem afinidade alguma, o que não podemos é privá-los de tentar senti-la, bem como as sensações e benefícios que podem provocar.

Comenta ainda que a arte musical sempre esteve presente na história da humanidade e na Antiga Grécia era importante para a formação integral do indivíduo. E que pesquisas feitas com surdos e a música mostraram que está proporciona benefícios ao passo que provoca sensações de prazer, conforto, alegria, realização, igualmente as pessoas ouvintes, bem como auxiliar no desenvolvimento cognitivo. É a forma que possibilita que "a música interna" se encontre com a externa, resultando numa sintonia que através do corpo resulta em movimentos.

Logo, a música permite que o corpo seja o captador de informações/sensações que são sentidas através da sintonia/vibrações transmitidas, o corpo se torna um meio de comunicação, e, por isso, é de grande relevância para o surdo o contato com a música. Silva e Rocha (apud Miranda, 2010) trás a informação de que na "87a Assembléia Científica e Encontro Anual da Sociedade de Radiologia da América do Norte", descobertas feitas pelo Dr. Dean Shibata, mostra que os surdos podem sentir vibração na mesma região do cérebro que as pessoas ouvintes:

As descobertas sugerem que a experiência que os surdos têm quando 'sentem' a música é similar à experiência de ouvir música para outras pessoas sem essa condição. A percepção das vibrações musicais pelos surdos é tão real quanto seu equivalente sonoro por serem ambos processados na mesma região do cérebro," afirmou Dr. Dean Shibata, professor de radiologia na Universidade de Washington e autor do estudo (SOCIEDADE DE RADIOLOGIA DA AMÉRICA DO NORTE, 28/11/2001).

A partir das vibrações emitidas pela música o surdo pode ter experiências de sensações como alegria, tristeza e outras emoções. Por este motivo, a música também pode ser entendida como uma forma de linguagem, aumentando sua capacidade de comunicação com o mundo, podendo dominar outros códigos como letra, ritmo, cadência, marcação e elementos relacionados à musicalidade. Porém, para isso é necessário que o surdo tenha o devido estímulo musical desde a infância. Lembramos aqui, que no âmbito escolar a música serve como lúdica e motivacional na aprendizagem para ouvintes e pode contribuir igualmente para os surdos.

Surdos e ouvintes podem e devem se unir através da música cada um com sua cultura e identidade, deixando de lado qualquer indiferença, explorando e conhecendo o que é música e 


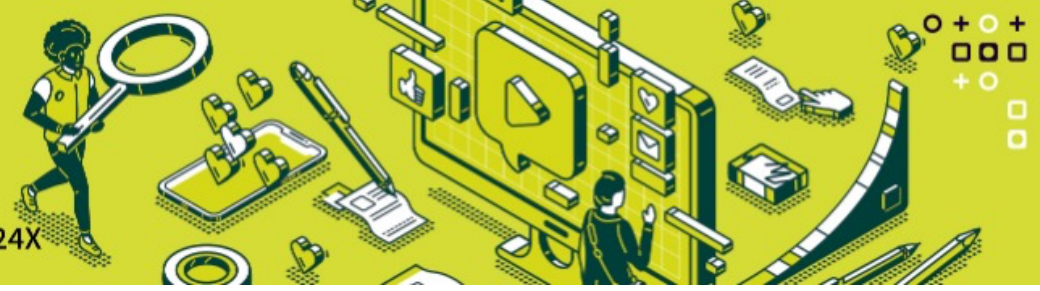

as forma de utilizá-la, experimentando-a sob diversas formas, seja como dança, teatro e outros, pois são formas de expressão e comunicação não verbal.

\subsection{TEATRO}

O Teatro surdo é outra manifestação artística que, com enredos nas práticas da cultura surda, exploram tanto as Línguas de Sinais como a visualidade e expressividade imagética que torna a apresentação bastante rica em detalhes. Existem apresentações bilíngues, apresentações sem textos (teatro visual, físico, mímico ou pantomima) em que sobressaem na apresentação o corpo do autor com sua expressividade nos movimentos, com ritmo nos gestos, jogos de luzes e linguagens manuais, caras e olhares etc. tendo de contrapartida experiências e concepções surdas. No teatro surdo os formatos são variados: apresentação em Língua de Sinais, peças bilíngues, apresentação sem textos verbais como teatros visuais ou físicos, mímicas e outros.

A dramaturgia de surdos é rica e feita em diversos países, com peças sobre os mais variados temas e para todos os tipos de público. Surdos e ouvintes de diferentes origens partilham experiências e reflexões sobre a língua gestual, artes visuais, textos dramáticos, recursos cênicos, cultura, política e identidade surda.

$\mathrm{O}$ ator surdo, na comunidade surda é visto com muito valor, pois, através dele novos públicos e futuros atores surdos poderão ser cultivados. Muitos artistas surdos têm trabalhos partilhados e difundidos em sites e redes sociais pela internet. $O$ teatro surdo favorece para enriquecer e projetar as culturas surdas para além de seus territórios, tornando uma arte rica e prazerosa.

A dramaturgia surda traz em suas narrativas momentos da história dos surdos, vivências do cotidiano, adaptações de clássicos universais, dentre outros temas que possam abrangir todos os públicos.Dentre os grupos teatrais brasileiros destacam-se Cia. Arte e Silêncio, Cia Teatral Mãos EmCena, Projeto Palavras Visíveis, Teatro Brasileiro de Surdos e Signatores. E dentre artistas teatrais, temos: Tibiriça Viana Maineri, de Caxias do Sul; Nelson Pimenta, Carioca, é o primeiro ator surdo a se profissionalizar no Brasil e estudou na National School of the deaf de Nova lorque em 1995; Sandro Pereira dos Santos, ator, instrutor de Libras e professor de expressão corporal e teatro para surdos; Rimar Romano e Sueli Ramalho, irmãos paulistas que fundaram a CIA Arte e Silêncio, que tem como objetivo sugerir um novo formato educacional através do teatro.

\subsection{DANÇA}

Na prática, dança é uma das melhores formas para se ensinar o potencial da expressão corporal. Ela surgiu da necessidade do ser humano transmitir suas emoções e sentimentos, sempre esteve presente na vida humana e consente qualquer indivíduo de praticá-la, pois acontece de dentro para fora, é uma transmissão de sentimentos que reconhecemos através de nossos corpos.

A dança é rica em seus diversos estímulos como: o visual, o auditivo, o cognitivo, o tátil, o motor e o afetivo. Na falta do sentido auditivo, a visão se apresenta aguçada captando qualquer movimento coreográfico através da observação. A comunicação do surdo se dá através da Língua de sinais, o que favorece este tipo artístico como sendo muito importante para eles por proporcionar mais uma forma de se manifestar, se comunicar. 


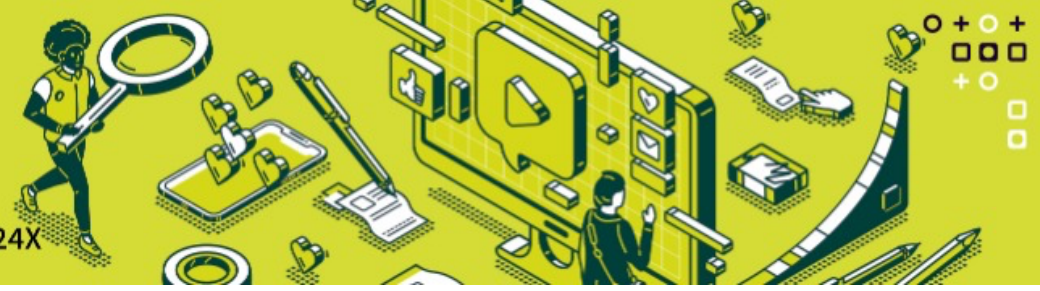

Quando o surdo dança, na maioria das vezes, seu próprio ritmo que está sendo apresentado, mostrando "um mundo desconhecido e valioso" (FUX, 1998, p. 48). Sendo assim, é necessário estimular a visão do surdo para que ele perceba o ritmo ambiental, acompanhando as percepções e colaborando para que através deste conhecimento compreenda seu próprio ritmo e expressão. Estes atos colaboram para que os surdos sejam mais receptivos por conta de sua sede de compreender o mundo que o cerca e mais felizes por compreender as imagens corporais que se transformam.

Ao dançar os surdos demonstram beleza e envolvimento para quem os assiste, de forma que sintam a velocidade, tonalidade, intensidade transformarem-se em movimentos, que através da dança, se expressam, comunicam, interagem, emocionam e permite que seja uma experiência prazerosa pela sua diversidade.

Segundo Anjos (2008, p. 16) "Toda ação humana envolve a atividade corporal. A dança é uma atividade dinâmica que leva o sujeito à descoberta do domínio do corpo e seu controle." Alguns dançarinos brasileiros: Claudio Mourão (Cacau) de Alagoas, Claudio Magalhães que é professor de dança de salão.

\subsection{PROdUÇõES AUDIOVISUAIS}

Em meio à tecnologia, filmes, curta-metragem, documentários, e vídeos caseiros que delimitam o tema surdez vêm aumentando e muitos são disponibilizados na internet ou em salas de exibição. O Instituto Nacional de Educação de Surdos (INES) é o maior produtor destes materiais, além de didáticos no Brasil.

Na cinematografia, além de outros filmes, temos o filme/documentário Gesto (2011) que aborda aspectos das comunidades surdas com a participação de atores surdos, produzido pelo realizador Antônio Borges Correia. Há ainda produções amadoras de Germano Dutra Júnior e Giuliano Robert, da Libra Filmes. Na categoria curta-metragem são muitas as produções, os mais conhecidos são: Ana (2004), de Mariana Magnavita e O resto é silêncio (2003), dirigido por Paulo Halm e produzido por Eduardo Nunes.

Por ser característica da cultura surda o uso da modalidade visual-espacial, a arte surda exige suportes de exibição, e, atualmente, a popularização de plataformas virtuais, sites de compartilhamento e armazenamento de vídeos, assim, enriquecem as interações comunicativas entre as comunidades surdas, contribuindo para criação e distribuição de produções culturais.

As produções audiovisuais em Língua de Sinais também se tornam uma fonte principal de divulgação da literatura surda, abrangendo tanto o público surdo quanto ouvintes, servindo de suporte para todos que se identificam com a comunidade surda ao compartilhar diversos tipos literários como: poesia visual, contação de história, piadas, contos, lendas, mitos entre outras narrativas em línguas de sinais, traduções de textos universais para a Língua de Sinais e a propagação da cultura surda.

Nos sites de armazenamento e compartilhamento de vídeos podemos encontrar canais que são de grande relevância para os estudos surdos e para a comunidade surda e ouvintes que se identificam ou estudam as comunidades surdas. Podemos encontrar entrevistas com surdos, surdos compartilhando sua vida em comunidade, família, educação, artes, poesias, rap, dança, contação de histórias e até grupos de estudos com o intuito de passar seus conhecimentos da Libras para quem tem interesse. 


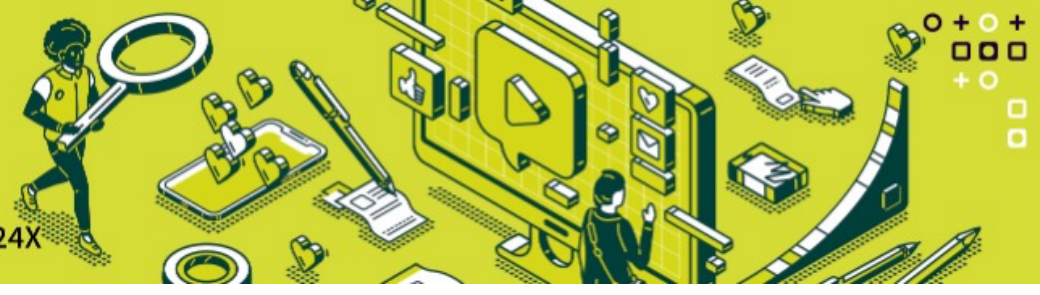

Em 2018, no dia 26 de setembro, dia do surdo, foi lançado o primeiro desenho para o público surdo "Min e as mãozinhas", criado por Paulo Henrique dos Santos, que trabalha com animação.

Na modalidade de vídeos registrados com tradução para Libras, podemos encontrar várias obras derivadas de contos clássicos e fábulas de Esopo como: Cinderela, A Bela adormecida, João e Maria, Os três porquinhos, Patinho Feio, Os três Ursos, O Curupira, A lenda da lara, A lenda da Mandioca, A galinha dos ovos de ouro, O Cão e o Lobo, O Corvo e a Raposa, A Cigarra e as Formigas, $\mathrm{O}$ Pastor e as ovelhas, $\mathrm{O}$ gato de Botas, Rapunzel, Alice no País das Maravilhas, A Lebre e a Tartaruga, A Raposa e as Uvas, Pinóquio, e outros.

\subsection{ARTES PLÁSticAS}

Nas artes plásticas a arte De'VIA tem grande relevância por sua riqueza estética e amplitude quanto à identidade das comunidades surdas. São produções livres, sem se prender à padrões, estilos ou escola definida, os artistas expressam em suas pinturas, gravuras, fotografias, instalações, esculturas suas experiências surdas, tendo como foco as produções a retratação do auditismo/ ouvintismo, as histórias e opressões das lutas surdas, as línguas gestuais, costumes, cultura surda, expressões faciais etc.

No Brasil as mais conhecidas artistas plásticas que retratam a sudez é Fernanda Machadom, artista plástica, atriz e poetisa surda e Billy Saga, um dos principais artistas De'VIA do Brasil, é rapper cadeirante, publicitário, artista plástico, Presidente da ONG Movimento SuperAção e consultor da ONG Mais Diferenças.

\section{A ARTE E SUA CONTRIBUIÇÃO PARA A COMUNIDADE SURDA}

"A arte surda é aquela que representa uma identidade cultural, assumindo uma expressão própria conforme a história". (Anjos, 2008, p. 9). As experiências culturais do povo surdo são construídas visualmente tendo em vista que o sentido sensorial da visão é o que possibilita aos surdos perceberem o mundo ao seu redor. Cabe ainda destacar que, segundo Strobel (2008), a cultura surda envolve as atividades do ser surdo, de ver, de perceber e de modificar o mundo por meio de práticas culturais que, por não terem audição e os elementos sonoros como referência, se constitui como distintas das desenvolvidas por grupos culturais ouvintes.

A arte surda se constitui como um artefato cultural do povo surdo. E serve como um reflexo cultural e identitário de uma comunidade que se expressa através da individualidade do artista surdo. Sem, contudo, abandonar a representação da visão do grupo. Através das artes visuais os surdos buscam encontrar-se com sua história, suas emoções, seu meio social, e sua língua.

O surdo, em contato com a arte e sua produção, vai se estabelecendo sujeito de experiência visual que percebe o que está à sua volta e utiliza a arte para descrever sua história, suas vivências e seus medos. O sujeito surdo é um sujeito cultural, pois, é permeado pela cultura na qual faz parte e a arte é um artefato cultural que o constitui, pois este consome a arte, faz circular e a utiliza para produzir o significado do ser surdo. Os surdos utilizam a visão para sua comunicação, na arte eles encontram a satisfação para expressarem o que sentem, pensam e vivenciam, eles se identificam muito com produções artísticas próprias da sua cultura e por meio da arte a comunidade surda e seus aspectos podem ser expressados, visualizados, vivenciados e expandidos para o mundo. 


\section{6. (RE)FLEXÕES}

O presente trabalho é resultado de uma pesquisa investigativa que possibilitou uma discussão a cerca do uso da arte na cultura surda e na importância de envolver o ensino das artes surdas como instrumento de inclusão nas escolas. Desta forma, assume-se também a beleza e a importância das inúmeras formas de existir, ser, e estar surdo ou deficiente auditivo.

Pretendemos aqui mostrar que a arte é uma experiência vivenciada e possível de ser valorizada como valor transformador, reconhecendo e promovendo as culturas surdas e, por conseguinte, contribuir pela luta dos direitos surdos para adquirir escolas ou salas com ensino bilíngue, pela inclusão e pela difusão das produções surdas nos diversos circuitos culturais.

Ficou evidente que os surdos têm muito potencial artístico e em diversos campos, e nossa intenção é incentivar para que existam mais oportunidades, para que as escolas possam despertar essas habilidades através da promoção de aulas de arte surda, possibilitando que cada indivíduo surdo possa identificar qual the provoca interesse e colocar em prática a forma que deseja se expressar, pois a arte pode possibilitar para os surdos bem-estar, liberdade, criatividade, comunicação, alegria, afetividade e aumenta a auto-estima.

\section{REFERÊNCIAS}

ANJOS, Rosa Virgínia Oliveira dos. Auto-estima resgatada pela identidade com artistas surdos. Universidade Federal do Rio Grande do Sul-Curso de Especialização em Pedagogia da Arte. Porto Alegre, 2008. Disponível em: <https://lume.ufrgs.br/handle/10183/15702> Aceso em: 22 jul 2019.

BRASIL. IBGE. Censo Demográfico, 2010.

CALDAS, Ana Luiza Paganelli. O filosofar na arte da criança surda: Construções e saberes. Dissertação(mestrado). Faculdade de Educação, Universidade Federal do Rio Grande do Sul Porto Alegre, 2006. Disponível em: < https://www.lume.ufrgs.br/bitstream/handle/10183/8735/000587787.pdf?sequence=1> Acesso em: 10 abr 2019.

CAMPELLO, A. R. S. Pedagogia visual / Sinal na educação dos surdos. In: QUADROS, R. M.; PERLIN, G. Estudos surdos II. Petrópolis, RJ: Arara Azul: 2007. p. 100-131.

CORNCINI LOPES, Maura (organizadora). CULTURA SURDA \& LIBRAS. [S. I.]: UNISINOS, 2012. $283 \mathrm{p}$.

CRUZ, Andreza Nunes Real da. Aula de arte com surdos: criando uma prática de ensino. Dissertação apresentada ao Programa de Mestrado Profissional em Artes - Profartes do Instituto de Artes da Universidade Estadual Paulista "Júlio de Mesquita Filho", São Paulo, 2016. Disponível em: https://repositorio.unesp.br/bitstream/handle/11449/143081/cruz_anr_me_ia.pdf?sequence =3> Acesso em: 10 abr 2019.

FUX, Maria. Dançaterapia. Tradução de Beatriz A. Cannabrava. São Paulo: Summus. 1988. Disponível em:<https://books.google.com.br/books?id=UCoaR33_WsC\&printsec=frontcover\&dq=isbn:8532303153\&hl=pt$B R \& s a=X \& v e d=0 a h U K E w j c g p a N m b r i A h V b I r k G H T w r D B s Q 6 A E I K T A A \# v=o n e p a g e \& q \& f=$ false $>$ Acesso em: 10 abr 2019. 


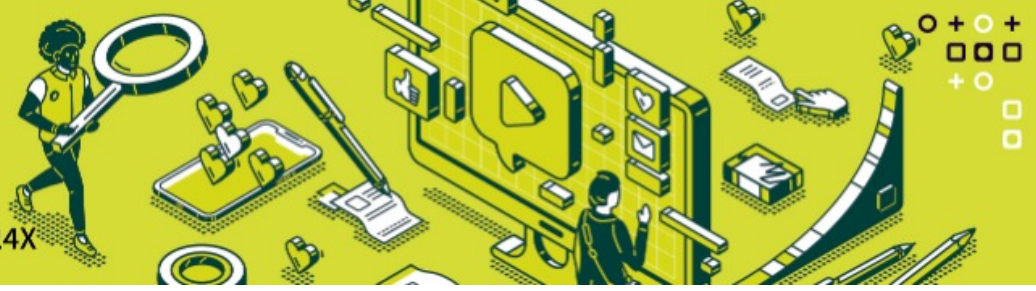

MANTOAN, Maria Tereza Egler. (Org.). 1997. A integração de pessoas com deficiência. São Paulo: Memnon. SENAC.

MULLER DE QUADROS, Ronice; PERLIN, Gladis (organizadoras). Estudos Surdos II. Petropolis, RJ: Arara Azul, 2007. 267 p. ISBN 978-85-89002-21-9.

MINISTÉRIO DA EDUCAÇÃO (Brasil). CNE/CEB. Institui Diretrizes Nacionais para a Educação Especial na Educação Básica. Resolução, № 2, de 11 de setembro de 2001. [S. I.], 31 nov. 2001. NAKAGAWA, Hugo Eiji Ibanhes. Culturas surdas: o que se vê, o que se ouve. Dissertação de Mestrado em Cultura e Comunicação. Faculdade de Letras da Universidade de Lisboa (FLUL) e a Universidade de Lisboa (UL), 2012. <https://core.ac.uk/download/pdf/12428313.pdf> Acesso em: 15 abr 2019.

NETO, Daniel Neves; JESUS, Luciana Pereira de e GOMES, Antenor Rita. Arte surda: interfaces entre cultura surda e cultura visual. Centro virtual de cultura surda-revista virtual de cultura surda, Edição 21, 2017. Disponível em: < http://editora-araraazul.com.br/site/admin/ckfinder/userfiles/files/1\%C2\%BA\%20Artigo\%20de\%20Santos\%20Net ○\%20\%26\%20Pereira\%20de\%20Jesus\%20\%20\%26\%20Gomes.pdf> Acesso em: 15 abr 2019.

PRESIDÊNCIA DA REPÚBLICA. Lei no 10.172, de 9 de janeiro de 2001. Aprova o Plano Nacional de Educação e dá outras providências. Diário Oficial, 10 jan. 2001.

PRESIDÊNCIA DA REPÚBLICA. Lei n¹0.436, de 24 de abril de 2002. Dispõe sobre a Língua Brasileira de Sinais - Libras e dá outras providências. Brasília: Diário Oficial, 25, abr. 2002.

PRESIDÊNCIA DA REPÚBLICA. Lei no 13.278/2016, de 2 de maio de 2016. Altera o 6o do art. 26 da Lei no 9.394, de 20 de dezembro de 1996, que fixa as diretrizes e bases da educação nacional, referente ao ensino da arte. Brasília: Diário Oficial, 3 maio 2016.

PRESIDÊNCIA DA REPÚBLICA. Lei no 9.394/1996, de 2 de maio de 2016. Estabelece as diretrizes e bases da educação nacional. Brasília: Diário Oficial, 23 dez. 1996.

QUADROS, Ronice Müller de. O tradutor e intérprete de língua brasileira de sinais e língua portuguesa / Secretaria de Educação Especial; Programa Nacional de Apoio à

Educação de Surdos - Brasília: MEC ; SEESP, 2004. PDF.

SÁ, Nídia Regina Limeira de. Surdos: qual escola?: qual escola?. 22. ed. Manaus: Valer e Edua, 2011. 320 p. ISBN 978-85-7401-558-3.

SILVA, Adriana de Moraes da; ROCHA, Évila Caroline Soeiro. Musicalidade e surdez: a música como referência de um estudo sobre o processo de interação do surdo com seu meio social ( $p$. 43-67). In: PINHEIRO, Moisaniel Oliveira; LIMA, José Willen Brasil; SILVA, Adriana de Moraes da (Orgs.). Surdez e inclusão educacional: diálogos acadêmicos acerca da educação de surdos. Porto Alegre- RS: Editora Fi, 2019.

SKLIAR, Carlos (org.). A Surdez: um olhar sobre as diferenças. Porto Alegre: Mediação, 1998. STROBEL, Karin. As imagens do outro sobre cultura surda. 2a Ed. Florianópolis: Editora da UFSC, 2008.

SUTTON-SPENCE, Rachel; Traduzido por Cayley Guimarães. Por que precisamos de poesia sinalizada em educação bilíngue. Educar em Revista, Curitiba, Brasil, Edição Especial n 2/2014, p. 111-128. Editora UFPR. PDF. 